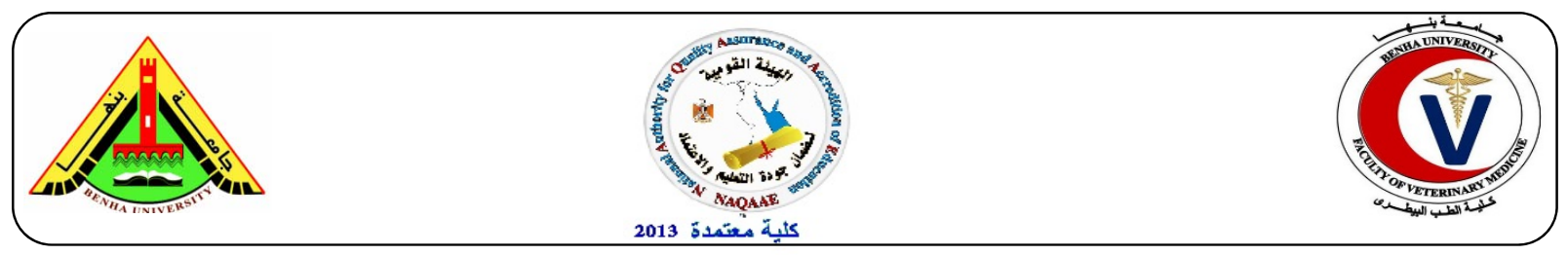

\title{
Biochemical changes associated with helicobacter pylori infection
}

\author{
Abd El- Maksoud, H.A. ${ }^{\text {, Fararh, K.M. }}{ }^{\text {b }}$, Metwaly, M. ${ }^{\text {a }}$ \\ ${ }^{a}$ Department of Biochemistry, Faculty of Veterinary Medicine, Benha ${ }^{b}$ Department of Clinical pathology, Faculty of \\ Veterinary Medicine, Benha University, Egypt.
}

\begin{abstract}
A B S T R A C T
The aim of the present study is to through lights on the biochemical relations between $\mathrm{H}$. pylori infection and the changes in serum Ammonia, Gastrin, Leptin, Amylase, Lipid profile, Iron, Total Iron Binding Capacity, Transferrin, Haptoglobin and Vitamin B12. 90- helicobacter pylori infected patients, and 20- clinically healthy subjects used as control all ages ranged between 25 to over 65 years are applied in the experiment. The result of the present study showed the association between serum Ammonia and Amylase, Gastrin and Leptin levels, in addition to serum lipid profile including (Total cholesterol, Triacylglycerol (TG), Low density lipoprotein - cholesterol (LDL-C) and High density lipoprotein - cholesterol (HDL-C), Iron status (Iron, Ferritin, Total Iron Binding capacity (TIBC) and Transferrin) in addition to Vitamin B12 and haptoglobin with helicobacter pylori infection. These parameters may all be regarded as predictors or risk factors for Gastritis, anemia, peptic ulcer, Gastric cancer and Coronary heart diseases in elderly patients. The findings of the present study suggest that, helicobacter pylori infection are primary interacting mediators in the anemia and different diseases of the stomach.
\end{abstract}

Keywords: H. pylori, Haptoglobin, Leptin, Ammonia, Serum iron, Ferritin, Anemia.

(http://www.bvmj.bu.edu.eg)

(BVMJ-31(1): 103-109, 2016)

\section{INTRODUCTION}

Helicobacter pylori (H. pylori) is a gramnegative pathogen that is widespread all over the world, infecting more than $50 \%$ of the world's population. with a predominant distribution in developing countries (up to 80\%) compared to industrialized ones (20\%-80\%) (Francesco et al., 2014). H. pylori causes chronic gastritis and peptic ulcer disease and it has been classified as a type I (definite) carcinogen since 1994. This organism has also been implicated in increasing the risk of developing gastric cancer, which is the second most frequent cause of cancer-related death (Adel et al., 2008). H. pylori-related gastritis and its effects on gastric physiology, affecting the normal process of iron absorption (Annibale et al., 2000). $\mathrm{H}$. pylori infection can cause a deficiency of vitamins like vitamin $B_{12}$ (Annibale et al., 2002). H. pylori infection has been associated with impaired energy homeostasis, lipid metabolism, elevated fasting insulin levels and insulin sensitivity (Francesco et al., 2014). This study was designed to study the relations between $H$. pylori infection and the changes in serum Ammonia, Gastrin, Leptin, Amylase, Lipid profile, Iron, Total
Iron Binding Capacity, Transferrin, Haptoglobin and Vitamin $\mathrm{B}^{12}$.

\section{MATERIAL AND METHODS}

\subsection{Patients:}

The study taken out on 1- 20 healthy person as control group 2- 90 patients infected with H. pylori, with age range between 25 and over 65 years, patients was selected from Gamal Abdel Nasser General Hospital in medicine and endemic medicine departments for treatment from continuous (pyloric burning) heart burning and upon analysis them blood samples for the presence of $\mathrm{H}$. pylori antibodies they are positive. Who classified according to age into four equal groups as follow: Group I: Control healthy individuals consist of 20-persons with ages ranged from 25 to over 65 years. Group II: Consisted from 30diseased patients with age ranged from 25 to 40 years. Group III: Consisted from 30-diseased patients with age ranged from 40-65 years. Group IV: Consisted from 30-diseased patients with age ranged from 65 to 80 years. 


\subsection{Collection of sample:}

Peripheral blood samples of all infected peoples and healthy peoples were collected. The collected samples were transferred to $5 \mathrm{ml}$ vacutainer tubes, stand about 30 minutes in room temperature, then centrifuged (at 3000 r.p.m for 5 minutes) and all available sera were stored at -20 ${ }^{\circ} \mathrm{C}$, diluted for biochemical analysis.

\subsection{Biochemical parameters:}

Plasma Ammonia (Neeley and Philipson 1988). Serum Amylase (Garaway et al.,1959). lipid profile [Total cholesterol (Fossati and Prencipe 1982), HDL-C (Allain et al.,1974), LDL-C (Falholt et al., 1973), VLDL-C (Friedewald 1973) and Triacylglycerol (Bucolo et al.,1973)]. Serum Gastrin (Goetze and Rehfeld 2003). Serum leptin (Titez 1995). Iron profile [Serum Iron (Henry 1974), serum Ferritin (Valberg 1980), total Iron Binding Capacity(TIBC) (Nissen,1972), Transferrin (Fairbanks and Klee 1987) and serum haptoglobin (Johnson et al.,1999). Serum Vitamin determined B12 (Sadasivam and Balasubraminan 1987). H. pylori antibodies determined by one step (Marshall et al,1985).

\subsection{Statistical analysis:}

Statistical analysis of the result was carried out using student's T-test, Data were expressed as mean \pm S.E. and were statistically analysed according to steel and torrie (1980).

\section{RESULTS}

\subsection{Biochemical parameters Table (1):}

The result revealed that significant increase in Ammonia in group III and group IV, and significant increase in Amylase in group IV as compared with the control group, while the Vitamin B12 was significantly decrease in group III and highly significant decrease in group IV as compared to control group.

\subsection{Hormonal parameters Table (2):}

There was significant increase in serum gastrin in group II and highly significant increase in group III and group VI as compared to the control group. On the other hand, there was significant decrease in serum Leptin in group III and group IV on comparison to the control group.

\subsection{Lipid profile parameter Table (3):}

There was significant increase in T.C in group III, IV in addition LDL-C level in group III showed highly significant increase in LDL-C level in group IV and non-significant increase in VLDL-C level. while it significantly decreased in HDL-C in group IV when compared to the control group.

\subsection{Iron status parameters Table (4)}

There was significant decrease in serum iron level in group IV and in ferritin level in group II, III. While there was highly significant decrease in ferritin in group IV as compared to the control group. On the other hand, there was significant increase in transferrin in group III, IV and TIBC in group II and there was highly significant increase in TIBC in group III and IV on comparison with the healthy group.

Table (1): Effect of Helicobacter pylori infection on plasma ammonia, serum amylase, Vitamin $\mathrm{B}_{12}$ and haptoglobin.

\begin{tabular}{lcccc}
\hline Parameter & $\begin{array}{l}\text { Ammonia } \\
(\mathrm{Umol} / \mathrm{L})\end{array}$ & $\begin{array}{l}\text { Amylase } \\
(\mathrm{U} / \mathrm{L})\end{array}$ & $\begin{array}{l}\text { Vitamin } \mathrm{B}_{12} \\
(\mathrm{Pg} / \mathrm{mL})\end{array}$ & $\begin{array}{c}\text { Haptoglobin } \\
(\mathrm{g} / \mathrm{L})\end{array}$ \\
\hline G I & $45.80 \pm 2.11$ & $88.50 \pm 1.79$ & $194.51 \pm 4.53$ & $137.181 \pm 4.11$ \\
G II & $51.80 \pm 1.91$ & $76.5 \pm 1.87$ & $115.00 \pm 2.97$ & $110.81 \pm 3.12$ \\
& & & & \\
G III & $63.19 \pm 2.21^{*}$ & $96.0 \pm 2.81$ & $101.11 \pm 3.12^{*}$ & $97.61 \pm 3.11$ \\
G IV & $86.89 \pm 2.75^{*}$ & $126.0 \pm 4.11^{*}$ & $91.78 \pm 3.11^{* *}$ & $91.8 \pm 2.71 * *$ \\
\hline \multicolumn{5}{c}{$* P<0.05$ means significant, ${ }^{* *} P<0.01$ means highly significant }
\end{tabular}

Table (2): Effect of Helicobacter pylori infection on serum Gastrin and plasma leptin.

\begin{tabular}{lcc}
\hline $\begin{array}{l}\text { Parameter } \\
\text { groups }\end{array}$ & $\begin{array}{c}\text { Gastrin } \\
(\mathrm{ng} / \mathrm{L})\end{array}$ & $\begin{array}{c}\text { Leptin } \\
(\mathrm{ng} / \mathrm{L})\end{array}$ \\
\hline G I & $71.00 \pm 1.91$ & $6.51 \pm 0.93$ \\
G II & $120.11 \pm 3.96^{*}$ & $4.91 \pm 0.77$ \\
G III & $125.0 \pm 4.75^{* *}$ & $4.02 \pm 0.87^{*}$ \\
G IV & $133.65 \pm 4.15^{* *}$ & $3.81 \pm 0.88^{*}$ \\
\hline \multicolumn{3}{c}{104}
\end{tabular}


Table (3): Effect of Helicobacter pylori infection on serum Lipid profile parameters.

\begin{tabular}{lccccc}
\hline Parameter & $\begin{array}{c}\text { T-C } \\
(\mathrm{mg} / \mathrm{dl})\end{array}$ & $\begin{array}{c}\text { Tg } \\
(\mathrm{mg} / \mathrm{dl})\end{array}$ & $\begin{array}{c}\text { HDL-C } \\
(\mathrm{mg} / \mathrm{dl})\end{array}$ & $\begin{array}{c}\text { LDL- C } \\
(\mathrm{mg} / \mathrm{dl})\end{array}$ & $\begin{array}{c}\text { VLDL-C } \\
(\mathrm{mg} / \mathrm{dl})\end{array}$ \\
\hline G I & $148.00 \pm 3.11$ & $101.51 \pm 1.91$ & $41.60 \pm 1.81$ & $86.10 \pm 2.58$ & $20.30 \pm 0.82$ \\
G II & $168.15 \pm 4.12$ & $128.50 \pm 3.81$ & $35.33 \pm 0.97$ & $107.12 \pm 2.59$ & $25.70 \pm 0.76$ \\
G III & $189.85 \pm 3.35^{*}$ & $143.51 \pm 4.25$ & $30.77 \pm 2.75$ & $130.38 \pm 2.93 *$ & $28.70 \pm 0.85$ \\
Group IV & $218.41 \pm 4.50^{*}$ & $149.18 \pm 3.87$ & $30.10 \pm 2.75^{*}$ & $158.50 \pm 3.51^{* *}$ & $29.84 \pm 0.78$ \\
\hline
\end{tabular}

Table (4): Effect of Helicobacter pylori infection on Iron status parameters.

\begin{tabular}{lcccc}
\hline Parameter & $\begin{array}{c}\text { Iron } \\
(\mathrm{Ug} / \mathrm{dl})\end{array}$ & $\begin{array}{c}\text { Ferritin } \\
(\mathrm{ng} / \mathrm{dL})\end{array}$ & $\begin{array}{c}\text { TIBC } \\
(\mathrm{Ug} / \mathrm{dL})\end{array}$ & $\begin{array}{c}\text { Transferrin } \\
(\%)\end{array}$ \\
\hline G I & $145.8 \pm 3.75$ & $211.81 \pm 6.51$ & $255.8 \pm 6.11$ & $2.93 \pm 0.08$ \\
G II & $102.75 \pm 3.01$ & $121.91 \pm 3.33^{*}$ & $286.8 \pm 5.81^{*}$ & $3.16 \pm 0.12$ \\
G III & $95.89 \pm 3.11$ & $118.81 \pm 2.8^{*}$ & $311.00 \pm 6.80^{* *}$ & $3.69 \pm 0.23^{*}$ \\
G IV & $90.81 \pm 2.80^{*}$ & $93.8 \pm 1.86^{* *}$ & $336.70 \pm 7.81^{* *}$ & $4.18 \pm 0.52^{*}$ \\
\hline
\end{tabular}

\section{DISCUSSION}

The significant increase in group III and group IV i.e. patients with ages 40 -more than 65 years as compared to the control was came in accordance with the results of Miyaji et al. (1997). while Chakrabarti et al., (2002) found no significant correlation between gastric juice ammonia concentrations and arterial ammonia levels in the study of 66 hepatic patients. The data suggest that liver impairment remains conclusive in ammonia disposal in patients with cirrhosis, whereas $\mathrm{H}$. pylori infection does not seem to play a major role in the pathogenesis of hyperammonemia in these patients, suggested that the decrease may be due to effect of antibiotic therapy on ammonia producing gut flora rather than H. pylori eradication. (Qin et al., 2012).

The significant increase in serum amylase in group IV May be due to pathophysiological implications in pancreatic diseases caused by $\mathrm{H}$. pylori infection Domínguez and Malfertheiner (2001) who found an increased pancreatic enzyme secretion in patients infected with H. pylori. This effect was attributed to the increased gastrin and reduced somatostatin release in these subjects due to direct action of $\mathrm{H}$. pylori and its toxins on the Gcells and D-cells in the antral mucosa. This increase in Amylase activity could be also related to the elevation of ammonia as stated by Jaworek et al., (2000) who demonstrate that $\mathrm{H}$. pylori infection of the stomach causes persistent elevation of ammonia (NH3) in gastric juice leading to hypergastrinemia and enhanced pancreatic enzyme secretion. This increase also could be attributed to the ductal cell proliferation as stated by Milutin et al., (2014) who observed that
H. pylori infection with antral predomination leading to an increase in pancreatic bicarbonate output and inducing ductal epithelial cell proliferation could contribute to the development of pancreatic cancer.

The significant increase of serum vitamin B12 in group III came in agreement with those recorded by Abdel et al., (2008) their studies findings strong evidence that $\mathrm{H}$. pylori infection is associated with cobalamin deficiency. Gastritis induced by $\mathrm{H}$ pylori infection predisposes to a more severe form of food-cobalamin malabsorption, also. Impaired ingestion of food peptides in the stomach interferes with disintegration of vitamin $\mathrm{B}_{12}$ and impairs its binding to intrinsic factor which may lead to the vitamin $\mathrm{B}_{12}$ deficient state (Kürşad et al., 2000). The high significant increase of serum Vitamin B12 in group IV may due to aging beside infection with $\mathrm{H}$. Pylori because many studies approved that The prevalence of vitamin $\mathrm{B}_{12}$ deficiency increases with age (Leischker and Kolb 2015). our results reported that there is high significant decrease in haptoglobin in group IV. Haptoglobin is an acute phase protein that binds haemoglobin released during the intravascular lysis of erythrocytes (Sharon et al., 2008).

The possession of different haem-utilization systems could greatly contribute to the virulence of $\mathrm{H}$. pylori since the ability of pathogenic microorganisms to scavenge iron and/or haem compounds from their host environment is fundamental for survival in the host and thus production of disease. Any free haem or free haemoglobin is bound by protein carriers: haptoglobin and haemopexin (Dennis et al., 1999). 
So the significant decrease in haptoglobin may be due to H. pylori scavenge heme compounds from their host. While other study Olga et al., (2010) reported that $\mathrm{H}$. pylori has haemolytic activity and has been found to adhere to red blood cells in capillaries in the lamina propria. Although $\mathrm{H}$. pylori has previously been reported to use hemoglobin for growth, the methods used previously did not permit the workers to prove that growth was not due to free heme present as a contaminant or due to other heme-containing complexes, such as heme-hemopexin or hemoglobin-haptoglobin.

By growing $\mathrm{H}$. pylori in serum-free medium supplemented with different concentrations of dialyzed hemoglobin, we showed that growth is not a result of free heme and that haptoglobin is not required. The significant decrease may be also due to the haemolytic activity of H. pylori. Neale et al., (1958) showed that in patients with excessive haemolysis clearance of haemoglobin from serum leads to absence or reduction of haptoglobin, So H. pylori infection lead to decreased serum haptoglobin (Shinton et al., 1965), which is agreement with our study. Serum haptoglobin estimation may therefore be of value in the diagnosis of haemolytic disease.

The results revealed that there was significant increase in serum Gastrin in group II and highly significant increase in group III and IV years compared to control group. This increase in serum gastrin levels may be due to decreased parietal cell activity in corpus as stated by Baysoy et al., (2003) as a result gastric acid decrease so hormone gastrin increases which stimulates the parietal cells to secrete acid. Our result agrees with Smith et al., (1990) and De Francesco et al., (2000) studies who shown that, $H$. pylori can increase circulating gastrin levels in the blood.it is unclear whether the hypergastrinemia that occurs in $\mathrm{H}$. pylori-infected individuals is attributable to hypochlorhydria, suppression of somatostatin, chronic gastritis, gastric atrophy or the direct induction of gastrin gene expression by the bacterium itself (Yun et al.,2014).

Vaananen and Vauhlxonen (2003) reported that serum gastrin -17 decrease with increase grading of antral atrophy among $\mathrm{H}$. pylori infected patients, which disagree with our results. There was significant decrease in leptin in group III and IV than control group. H. pylori colonization was associated with reduced circulating leptin levels, perhaps by inhibiting their gastric production as stated by Jatin et al., (2008). This decrease in serum leptin maybe due to greater degree of antral atrophy/intestinal metaplasia in $\mathrm{H}$. pylori compared with H. pylori- subjects. Alternatively, H. pylori + persons may have less adiposity relative to BMI and therefore lower serum leptin levels compared with $\mathrm{H}$. pylori - persons. A recent study of indigenous Amerindians provided evidence that $\mathrm{H}$. pylori+ subjects had more athletic body morphometry, consistent with this hypothesis (Marini et al., 2007). On the other hand, Azar and Hamid (2011) reported that there was no significant relationship between serum H. Pylori IgG antibody titre and the age of the patients, BMI and serum leptin level. The finding that leptin was localized in the oxyntic gland area, which is rarely colonized by the organism, suggests that $\mathrm{H}$ pylori itself may not affect gastric leptin levels (Mix et al., 2000). While there were other studies disagree with our results such as Francesco et al., (2014) who found that Subjects with $H$. pylori infection have higher concentration of leptin than controls. and this phenomenon may contribute to the occurrence of dyspeptic symptoms and appetite alteration.

Our results revealed that non-significant increase in triacylglycerol and VLDL-C, while significant increase in LDL-C in group III and in Total cholesterol in group III and IV, i.e. patients with age 40 to over 65 years, also show highly significant increase in LDL-C and significant decrease in HDL-C in group IV i.e. patients with more than 65 years compared to the control group as shown in table (3). This hyperlipidaemia in infected patients with H. pylori could be attributed to the effect of the infection on lipid metabolism as stated by Al-Fawaeirlet al., (2013) who observed that $\mathrm{H}$. pylori seropositive subjects have higher serum triglyceride, total cholesterol and LDL-C concentrations when compared to healthy subjects. The findings support the hypothesis that chronic infections may modify lipid metabolism in a way that could increase the risk of atherosclerosis (Aino et al., 1999).

Some earlier studies Murray et al., (1995) and Niemela et al., (1996) have suggested an association between $H$. pylori infection and cardiovascular diseases. The significant decrease in serum iron in group IV i.e. patients over 65 years may be due to H. pylori infection impaired iron uptake as stated by Durdi et al., (2011). This role is maybe related to directly competing with the host for available iron or by impairing iron uptake (Durdi et al., 2011).

H. pylori may impair iron metabolism. It is possible that $\mathrm{H}$. pylori may both directly compete with the host for available iron by impairing its uptake. In the present study, we found that the mean of ferritin was significantly lower in $\mathrm{H}$. pylori positive group than H. pylori negative group. These data confirm an earlier study (Zakaria and Ahmed 2009). 
The Low level of serum ferritin may be due to Uptake of iron by the Helicobacter pylori organism may contribute to iron deficiency associated with Helicobacter pylori infection. Like many bacteria, Helicobacter pylori require iron as a growth factor, and it possesses a $19-\mathrm{kDa}$ iron-binding protein resembling ferritin (Pfr), that may play a role in storage of excessive iron by the bacteria. Moreover, since these bacteria have a high turnover rate, a large amount of iron may be lost in stools in the form of dead bacteria (Seo et al., 2002).

Our results were in line with finding of Ghada (2015) reported that $\mathrm{Hb}$ levels, serum iron, serum ferritin were lower and TIBC was higher in $\mathrm{H}$. pylori-infected cases than negative ones. while (Hsiang-Yao et al., 2013) reported that The levels of hemoglobin, serum iron and ferritin, and TIBC remain unaffected after chronic Hp infection. Also Durdi et al., (2011) observation disagree with our results indicated that total iron-binding capacity in $\mathrm{H}$. pylori positive group were lower than in the $\mathrm{H}$. pylori negative group. This role is maybe related to directly competing with the host for available iron or by impairing iron uptake.

The significant increase in serum transferring were in agreement with Harris et al., (2013) observed that Enhanced erythropoiesis and iron deficiency have both been reported to elevate the serum transferrin receptor level. There was a very highly significant association between Helicobacter pylori infection and refractory iron deficiency anaemia (Zakaria and Ahmed 2009). The mechanisms by which $\mathrm{H}$. pylori might cause ID/IDA are still not determined; but, gastric acid is essential for iron absorption by reducing the ferric iron to a more soluble and absorbable ferrous iron form (Zimmermann and Hurrell et al., 2007).

While some studies from developing countries failed to find such an association. A recent report from Bangladesh also concluded that H. pylori was neither a cause of IDA, iron deficiency nor a reason for treatment failure of iron supplementation in young Bangladeshi children (Sarker et al., 2008). These studies documented no statistically significant association of $\mathrm{H}$. pylori infection with anemia or low iron status. This studies suggested that the presence of anemia and low iron status in developing countries might be contributed by many factors together. Populations in less developed countries are frequently susceptible to deficiency of various micronutrients needed for hemoglobin synthesis other than iron. These may include folic acid, vitamin B12, vitamin $\mathrm{A}$ and low protein intake from poor quality diet might have contributed to the development of anemia or low iron status among these population (Sarker et al., 2004).

\section{CONCLUSION.}

H. pylori infection associated with increased ammonia, amylase and gastrin level which are associated with precipitate hepatic encephalopathy, pancreatic disease and gastric cancer. Also this infection change serum lipid concentration, increasing the risk of atherosclerosis and ischemic heart disease. H. pylori is probably responsible of IDA (iron deficiency anemia) and pernicious anemia through several mechanisms and affect regulation of appetite.

\section{REFERENCES}

Abdel, Salam S., Mohammad, A., Wael, H., and Tamer, A. 2008. Helicobacter pylori, a causative agent of vitamin B12 deficiency J Infect Developing Countries. 2(5): 346-349.

Aino, L., Aini, B., Simo, N., Juhani, H., and Maija, L .1999. Association of Helicobacter pylori infection with elevated serum lipids Atherosclerosis 142: 207-210

Allain, C.C., poon, L.S., Chan, C.S., Richmond, W., Fu, C. 1974. Enzymatic determination of total serum cholesterol. Clin chem. 4:470475

Annibale, B., Capurso, G., Martino, G., Grossi, C., Delle, Fave G. 2000. Iron deficiency anaemia and Helicobacter pylori infection.Int J Antimicrob Agents 16: 515519 .

Annibale, B., Capurso, G., Delle, F.G. 2002. Consequences of Helicobacter pylori infection on the absorption of micronutrients. Dig Liver Dis 34 (2): S72S77.

Azar, B., and Hamid, N. 2011. Association of Helicobacter Pylori IgG Antibody with Various Demographic and Biochemical Parameters in Kidney Transplant Recipients Saudi J Kidney Dis Transpl .22(6):11151120.

Baysoy, Gökhan, Ertem, Deniz ,Ademoğlu, Eivn, Kotiloğlu, Esin, Keskin, Sabiha , Pehlivanoğlu and Ender 2003. Gastric Histopathology, Iron Status and Iron Deficiency Anemia in Children with Helicobacter pylori Infection, Gastroenterology and Nutrition, Marmara University School of Medicine, Tophanelioglu Cd. 13-15, 81190 Altunizade-Istanbul, Turkey.

Bucolo, G., and David, H .1973. Quantitative determination of serum triglycerides by the 
use of enzymes, Clin Chem may; 19(5): 47682

Chakrabarti, P., Zullo, A., Hassan, C., Pandit, A, Chowdhury, A. and Santra, A. 2002. H. pylori, gastric Juice and arterial ammonia levels in patients with cirrhosis. $\mathrm{Br}$. Gastroenterl 54: 455-2.

De Francesco, V., Zullo, A., Rinaldi, V., Hassan, C., Ballanti, P., Winn, S., Diana, F., Morini, S., Attili, A.F. 2000. Relationship between antral lymphocyte density and basal gastrin levels in patientswith Helicobacter pylori infection. Dig Liver Dis .32:676-681.

Dennis, J. W, Janneke, M., Christina, M.J.E. Vandenbroucke-Grauls and Johannes, G. K. 1999. MuIt iplehaern - utilization loci in Helicobacter Pylori MicrObiology 145: 68 1-688.

Durdi, Q., Maryam, S., and Shahreyar, S. 2011. Association between helicobacter pylori infection and serum iron profile Caspian $\mathrm{J}$ Intern Med 2(3): 266-269

Fairbanks, V.F., and Klee, G.G.1987.biochemical aspects of haematology. In textbook of clinical chemistry; In W. titez, Ed. Philadelphia, W.B. Saunders Company, PP. 1578-1582.

Fossati, P., and Prencipe, L. 1982.Serum triacylglycerol determined colorimetrically with an enzyme that produces hydrogen peroxide. Clin Chem. 1: 2077-2080.

Francesco, F., Tortora A., Di, R. T., D'Angelo G., and Gianluca, I. 2014. Role of Helicobacter pylori infection on nutrition and metabolism World J Gastroenterol 20(36): 12809-12817

Friedewald, W.T. 1973. Estimation of concentration of low-density lipoprotein cholesterol in plasma without use of the preparative ultracentrifuge. Clin Chem. 18: 499-502

Garaway, W.T. and Ame, J., 1959. Amylase determination method. Clin Pathol, 32: 9799.

Ghada, M. 2015. Helicobacter pylori and anemia with

pregnancy.AinshamsUniversity,CairoObste trics,Gynaecology. [accessed May 13,].

Goetze, J.p., and Rehfeld, J.F.2003.Impact of Assay Specificity in Gastrinoma Diagnosis. Clin Chem; 49: 333-334.

Harris, P.R., Serrano, C.A., Villagra', n. A., Walker, M.M., and Thomson, M. 2013. Helicobacter pylori-associated hypochlorhydria in children, and development of iron deficiency. J Clin Pathol 66: 343-347.
Henry, R.J. 1974. Clinical Chemistry, Principles and techniques, 2nd ed., Harper and Row: 543-695.

Hsiang-Yao, S., Fu-Chen ,K., Sophie, S. , YiChang, L. and Meng-Chieh, W.2013. Helicobacter pylori Infection and Anemia in Taiwanese Adults. Gastroenterology Research and Practice 2013 (2013), Article ID 390967, 4 pages in Health and Disease, 8-59.

Jatin, R., Fritz, F., Peter, L. Shue, Michelle, S. Mourad, Zhiheng P., Asalia Z. Olivares, de Perez, Guillermo I., Perez-Perez, Chi-Hong, T., and Martin, J. 2008. Leptin and Ghrelin in Relation to Helicobacter Pylori Status in Adult Males. Endocrinol Metab. 93(6): 2350-2357

Jaworek, J., Bilski, J., and Jachimczak, B. 2000. the effects of ammonia on pancreatic enzyme secretion in vivo and in vitro journal of physiology and pharmacology. 51(2): 315-332.

Johnson, A.M.; Rohlfs, E.M and Silverman, L.M. 1999. proteins. In: Burrtis CA, Ashwood, E.R., eds. Tietz Text-book of clinical chemistry. hiladelhia: WB Saunders Company, pp. 477-540.

Kürşad, K., Cengiz, B., Ali, U.U., Türker, Ç., Ferit, A., Mustafa, G., Rífkí, F. and Atilla, Y. 2000. Helicobacter pylori-Is It a Novel Causative Agent in vitamin B12 Deficiency? Arch Intern Med. 160(9): 1349-1353.

Leischker, A.H., and Kolb, G.F.2015.[vitamin B12 deficiency in the elderly]. Z Gerontol Geriatr. 2015 Jan;48(1):73-90. doi: 10.1007/s00391-014-0837-0.

Marini, E., Maldonado-Contreras, A.L., Cabras, S., Hidalgo, G., Buffa, R., Marin, A.G., Racugno, W., Pericchi, L.R., Castellanos, M.E., Groschl, M., Blaser, M.J., Dominguez-Bello M.G. 2007. Helicobacter pylori and intestinal parasites are not detrimental to the nutritional status of Amerindians. Am J Trop Med Hyg 76: 534 540

Marshall, B.J., Gechie, M., Rogers, D.B., and Glancy, R.G.1985. Pyloric Campylobacter infection and gastroduodenal disease. Med. J. Australia.149: 439-44.

Milutin, B., Nikola, P., and Johannes, M. 2014. Helicobacter pylori and pancreatic diseases World J Gastrointest Pathophysiol. 5(4): 380-383.

Mix, H., Widjaja, A., and Jandl, O.2000.Expression of leptin and leptin receptor isoforms in the human stomach. Gut $.47: 481-6.27$. 
Miyaji, H., Ito, S., Azuma, T., Ito, Y., Yamazaki, Y., Ohtaki, Y. 1997. Effects of Helicobacter pylori eradication therapy on hyperammonaemia in patients with liver cirrhosis. Gut. 40: 726-30.

Murray, L.J., Bamford, K.B., O'Reilly, D.P., McCrum, E.E., and Evans, A.E. 1995.Helicobacter pylori infection: relation with cardiovascular risk factors, ischaemic heart disease, and social class. Br Heart J. 74:497-501.

Neeley, W.E., and Phillison , J.1988. Automated enzymatic method for determining ammonia in plasma, with 14-day reagent stability. clin chem. 34(9): 1868-9.

Niemela, S., Kartunen, T., Korhnonen, T., Laaea, E., Karttunen R. and Ikaheimo, M. 1996. Could Helicobacter pylori infection increase the risk of coronary heart disease by modifying serum lipid concentration? Heart. 75:573-5.

Nissen, M.1972. Colorimetric method for determination of Total iron binding capacity (TIBC). Clin. Chim Acta 40:219-224.

Qin, S.Y., Jiang, H.X., Ning, H.J., Nie, H.M., Tao, L. and Hu, B.L. 2012. Effect of Helicobacter pylori eradication on blood ammonia levels in cirrhotic patients: a systematic review. Hepatogastroenterology 59(120): 2576-81.

Sadasivam, S., and Balasubraminan, T. 1987. In: practical Manual in Biochemistry Tamil Nadu Agricultural University Coimbatore pp14.

Sarker, S.A., Davidsson, L., Mahmud, H., Walczyk, T., Hurrell, R.F, Gyr, N. and Fuchs, G.J. 2004: Helicobacter pylori infection, iron absorption, and gastric acid secretion in Bangladeshi children. Am J Clin Nutr; 80: 149-153.

Sarker, S.A, Mahmud, H., Davidsson, L., Alam, N.H, Ahmed ,T., Alam, N., Salam, M.A.,
Beglinger, C., Gyr, N., Fuchs, G.J. 2008. Causal relationship of Helicobacter pylori with iron-deficiency anemia or failure of iron supplementation in children. Gastroenterology 135: 1534-1542.

Seo, J.K., Ko, J.S., and Choi, K.D. 2002. Serum ferritin and Helicobacter pylori infection in children: a seroepidemiologic study in Korea. J Gastroenterol. Hepatol. 17: 754-7.

Smith, J.T, Pounder, R.E., Nwokolo, C.U., Lanzon-Miller, S., Evans, D.G., Graham, D.Y., Evans, D.J.1990.Inappropriate hypergastrinaemia in asymptomatic healthy subjects infected with Helicobacter pylori. Gut; 31: 522-525.

Steel, R.G.D. and Torrie, J.H. 1980. Principles and Procedures of statistics, Second Edition, New York: McGraw-Hill Book Co.

Titez, N.W.1995. Clinical guide to laboratory tests. 3rd ed. Philadelphia: WB Saunders, pp. 268273.

Vaananen, H., and Vauhlxonen, M. 2003. Non endoscopic diagnosis of atrophic gastritis with a blood test. Correlation between gastritis histology and serum levels of gastrin 17 and pepsinogen I. a multicentre study. European Journal of Gastroenterology and hepatology 15: 885-91.

Valberg, L.1980. Plasma ferritin concentration, their clinical significance and relevance to patient care. J. Canada. MedicineAssiciation, 122: 1240-1247

Zakaria, N.h., and Ahmed, E.A.2009. Investigation of a possible association between refractory iron deficiency anaemia to an underlying remote helicobacter pylori infection. J Egypt public Health Assoc 84: 141-68.

Zimmermann, M.B. and Hurrell, R.F.2007.Nutritional iron deficiency. Lancet 370:511-520. 